\title{
Consumer reactions to online behavioural tracking and targeting
}

Received (in revised form): 12th November, 2007

\section{Pamela L. Alreck}

is a professor of marketing in the Franklin P. Perdue School of Business at Salisbury University, Salisbury, MD, USA. She received her Doctorate from the US International University and formerly taught at San Diego State University and Bentley College, Boston. She is author of The Survey Research Handbook, Why They Buy: American Consumers Inside and Out, and numerous academic papers.

\section{Robert B. Settle}

is a professor of marketing in the Franklin P. Perdue School of Business at Salisbury University, Salisbury, MD, USA, and Emeritus Professor of Marketing at San Diego State University. His doctorate is from the University of California, Los Angeles. He is an author of Why They Buy: American Consumers Inside and Out, The Survey Research Handbook, and numerous academic papers.

Keywords behavioural targeting, consumer behaviour, database marketing, dynamic pricing, electronic commerce, target marketing

\begin{abstract}
This study measures three aspects of consumer reactions to online behavioural tracking and targeting: (1) What consumers know or believe about online behavioural tracking and targeting and the practices associated with it, (2) the nature of their opinions or evaluations regarding these strategies, and (3) the consumers' online shopping actions or behaviour in view of what they believe and how they feel about online tracking and targeting. The findings indicate a higher level of awareness of tracking and targeting than the existing literature suggests. Reactions to it are largely negative, although not strident. Dislike of tracking and targeting does not appear to have greatly inhibited online browsing or shopping activities.

Journal of Database Marketing \& Customer Strategy Management (2007) 15, 11-23. doi:10.1057/palgrave.dbm.3250069; published online 10 December 2007
\end{abstract}

\footnotetext{
Pamela L. Alreck

Franklin P. Perdue School of Business

Salisbury University Salisbury, MD 21801, USA Tel: +1 3024365580 ; Fax: +1 3024365580 ; e-Mail: PLAlreck@Salisbury. EDU
}

\section{INTRODUCTION}

In the beginning, e-commerce promised the coming of the 'perfect' market at last. With the introduction of product search and price comparison websites or the so-called shopping bots, it appeared that technology was about to achieve what economists could only assume in the past: namely, near perfect information. ${ }^{1,2}$

\section{Behavioural tracking}

Lately, it would appear that what technology has provided, it may now take away. By depositing 'cookies' on individual shopper's computer and/or by recording a visiting shopper's computer IP address, online marketers obtained the ability to track the shopper's behaviour, not only while at the site but also coming and going. ${ }^{3}$ Behavioural tracking provides the data for 'tailoring' pages, offers, and prices to the behavioural characteristics of the individual shopper. ${ }^{4}$

The online shopper sits comfortably at the keyboard, comparing products and prices from one online seller's site to another, or perhaps with the help of a shopping bot, confident that the 'best' deal has been identified. ${ }^{5,6}$ Meanwhile, several of the online marketers whose sites were 
visited may have deposited cookies on the shopper's computer and perhaps received data from previously deposited cookies. ${ }^{4,7}$ Hence, the 'best' deal may be only the best available at this particular time for this particular visitor with this particular history and this particular avenue of arrival at the site. In other words, it may not be the best deal at all, in any global sense of the word.

Behavioural tracking and price targeting have grown rapidly in popularity among marketers and are very likely to continue to gain acceptance. ${ }^{8}$ There are several benefits or reasons for online sellers of consumer goods to invest in the software and maintenance to track and target shoppers.

\section{Boosting sales}

There are potential increases in sales revenue and profits inherent in tailoring offers and prices to the buyer's behaviour. At its core, market segmentation and target marketing are all about this kind of differential treatment of a broad market. ${ }^{9}$ With conventional target marketing, the assumption is that it is more lucrative to gain deeper penetration in specific segments than to attain only shallow penetration among the entire market by trying to be 'all things to all people.' But in the case of online tracking and targeting, as with database marketing in general, the 'segments' consist of individual consumers.

\section{Experimentation}

Experimenting with offers and prices is nothing new to direct marketers. For decades, they have been using 'split-run' methods to test appeals, offers, prices, and media, among other things. The technology to do behavioural tracking and targeting has only enhanced that ability to experiment, and in many cases, made it more economical to do so. For instance, an online marketer might offer a set of prices randomly to shoppers visiting the site to estimate the demand curve to the product. Alternatively, various appeals, page layouts, featured goods, 'specials', and deals might be tested. In such cases, the objective is to determine what sells best, and then establish that set of characteristics as the standard for that product in the coming time period.

\section{Winning new customers}

It is an axiom of direct marketing that investment in the first transaction, to obtain a new customer, typically has long-time benefits in terms of the lifetime value of the customer. ${ }^{10}$ By identifying visitors to an online marketers site and distinguishing those who have purchased previously from those who are potential new customers, the newcomer can be wooed with special deals and incentives, including discounted prices, free shipping, and the like. Doing so is based on the premise that the customer is likely to return and purchase at prices more lucrative to the seller.

\section{Building customer loyalty}

This is, of course, the opposite side of the coin from the effort to win new customers. In this case, the strategy is to reward existing customers for coming back. ${ }^{11-14}$ Again, the existing customers must be distinguished from newcomers, but with this policy, the existing customers get the special deals, prices, or incentives. The offers and prices may be conditioned on how frequently the customer purchases, the volume of purchases, the duration of patronage, even the period of time since the last purchase, in order to win back inactive former buyers. ${ }^{15}$

\section{Meeting competitor prices}

Tracking technology allows online merchants to identify visitors to the site who come directly from online product search and price comparison sites or shopping bots. ${ }^{16}$ Some online marketers believe that such customers are likely to be more price-sensitive than those who come to the site directly or form other sites. Thus, they may offer such visitors, and especially 
the first-time visitors, price discounts, special deals, or incentives.

\section{Recover referral costs}

Product search and price comparison sites often list links to online merchants above, below, or to the right of the actual search results. These 'ads' are keyed to words or phrases in the search string, based on a contractual arrangement between the search site and the online merchant. Each time a shopper clicks on one of those links outside the regular search results, that merchant is charged a fee, whether or not the shopper makes a purchase. In fact, only a very small fraction of such visitors do buy. Some online merchants either charge a higher price to come to their site by this route or, more likely, do not offer special incentives that might be available to those who come to them via a different route.

\section{Augment email promotions}

Bombarded with ads and other messages, most consumers open only a small proportion of the e-mail they receive. They respond to an even smaller fraction of offers. E-commerce merchants who track the behaviour of visitors to their sites can and sometimes do use these data to target e-mailings. Recipients who are addressed by name or offered products or services related to previous purchases or to goods they have examined on the sender's website are more likely to respond than those who receive 'blind' mailings. ${ }^{17,16}$

\section{Making a 'Second Offer'}

Merchants who track consumer behaviour at their sites may record what items are left in abandoned shopping carts. The assumption is that such shoppers were close to making a purchase, and then changed their minds. Perhaps a discount or other incentives, such as free shipping, would push them over the edge, resulting in successful conversion. If the merchant has or can obtain the shopper's e-mail address, this kind of 'second offer' can be provided, containing a link to the site and even the specific page listing the product of interest to the shopper. ${ }^{15}$

\section{Marketers' perspective}

Online marketers using the new track and target technology typically see it as the ultimate micromarketing tool. ${ }^{18}$ Implantation of cookies coupled with the establishment, maintenance, and enhancement of a customer plus shopper database provides the potential for individualised targeting.

Online merchants are also quick to purport that tracking and targeting programmes are in the best interest of the consumer, as well as the marketer. Shoppers are provided with offers for the goods and services in which they are most interested. They receive fewer messages and offers for merchandise for which they have no need or desire. Consumers gain information about the goods they need and want, information they would not otherwise receive or would have to search out. Such claims are certainly true, to some degree. On the other hand, it is doubtful that consumers are quite so sanguine about tracking and targeting practices, as are the online merchants.

\section{Consumer reactions}

Both anecdotal reports from the popular press and empirical evidence reported in the academic literature indicate that public reactions to online behavioural tracking and price and offer targeting range from shear disbelief to vehement outrage. ${ }^{19}$ Many consumers are reported to believe that price targeting is actually illegal. One study reported, 'Sixty-four per cent of American adults who have used the Internet recently do not know it is legal for "an online store to charge different people different prices at the same time of day." "The same study indicated, 'Seventy-six per cent agree, "It would bother me to learn that other 
people pay less than I do for the same products.",20

Quick to pick up on public fear, advocacy groups such as The Center for Digital Democracy and US Public Interest Research Group filed a brief with the FTC asking for tighter restrictions on advertising online. While the main area of focus of most studies and reports is concern for information privacy, the issues of disclosure and fairness in pricing are also a major factor. A representative of the US Public Interest Research Group proclaimed, 'The emergence of this online tracking and profiling system has snuck up on both consumers and policymakers and is much more than a privacy issue' (emphasis added). ${ }^{21}$

Public concern and institutional response have not gone unnoticed by direct and interactive marketers. At an FTC public hearing in late 2006, Direct Marketing Association President John Greco stipulated, 'We need to determine from what we want to protect (consumers) beyond the areas upon which everyone agrees. ${ }^{22}$ His statement highlights the fact that public concerns regarding e-commerce constitute a package of beliefs, preferences, and fears.

\section{Research questions}

The questions addressed by this study are based on the traditional three-component attitudinal model. The study seeks to learn (1) what consumers know or believe about online behavioural tracking and targeting and the practices associated with it, (2) the nature of their opinions and evaluations regarding these strategies, and (3) the consumers' online shopping actions or behaviour in view of what they believe and how they feel about online merchandisers.

\section{METHODOLOGY}

A survey of 1,135 adult consumers residing in the Mid-Atlantic region of the US was conducted in March 2007. The questionnaires were delivered and retrieved by university student field workers who were assigned a quota, based on the age and sex of the respondents. To qualify for participation, respondents were required to have access to a computer at home and connection to the internet. They must also have made at least two online purchases in the past year. Although no minimum value was specified in the quota, they were asked to report the number and value of purchases in the questionnaire.

\section{Survey questionnaire}

Based on perusal of recent industry and academic papers describing behavioural targeting, 16 statements about what online marketers can and may do were composed. These items, worded in layperson terms, were listed in random order in the selfadministered survey questionnaire. In this and subsequent sections, the number of items was limited to 16 to avoid fatigue bias while providing a balance between breadth of content and depth of detail. A five-point scale was depicted to the right of each statement with extremes labelled Definitely True and Definitely False. The midpoint was labelled Not Sure. Respondents were asked to circle a number beside each statement to indicate what they thought about it regarding online marketers who sell consumer goods on the web.

On the following page of the questionnaire, respondents were asked to indicate their agreement or disagreement with a second set of 16 statements on a five-point scale with extremes labelled Strongly Agree and Strongly Disagree. The midpoint on this scale was labelled Don't Know. The statements were composed of what online shoppers might or might not advocate or support and how they evaluated what they knew, based on content gleaned from the current online marketing literature.

The third questionnaire page included a list of 16 online shopping actions to which respondents indicated how often they performed each using a five-point verbal frequency scale. The scale points were 
labelled Very Often, Often, Sometimes, Rarely, and Never. The actions listed included such common online behaviour as using search engines to find products, writing product review, or registering with an online merchant.

In addition to these behavioural measures, 10 popular product search and price comparison websites and 10 coupon supplier websites were each listed in alphabetical order. Respondents indicated how often, if at all, they had visited each site during the past year. They were also questioned about their mode of connection to the internet, frequency of computer use, internet and web activity, and online shopping and buying behaviour.

Lastly, respondents reported their demographic status. They indicated their sex, age, marital status, education level, employment category, occupational category, home ownership, and family income in the demographic section of the questionnaire. These data measured field worker adherence to quota specifications, in addition to indicating the nature of the population represented.

\section{RESULTS}

\section{Sample demographics}

About half of the sample was of each sex, with roughly a third under 35 years of age, between 35 and 50, and over 50 years of age, reflecting the sample quota specifications. Just over half were married. About a fourth had only a high school education and a slightly higher proportion had some college. A third were college graduates and the remaining 15 per cent had postgraduate education.

Just over a third of respondents were not employed outside the home. Of those who were employed, nearly two-thirds were employed by a company, while the remainder were employed by government, in education, or were self-employed. About 45 per cent of employed respondents reported professional, executive, or managerial occupations and a slightly smaller proportion were engaged in technical, administrative, marketing, or sales occupations. Only about 15 per cent had skilled or semi-skilled jobs.

Over two-thirds of the respondents were homeowners. Less than a third of the respondents withheld their income. Of those reporting income, a third had annual family incomes of over $\$ 100,000$ while slightly fewer than a third had family incomes of less than $\$ 60,000$. Thus, the responding sample tended to be more educated, affluent, and engaged in more up-scale occupations than the general population from which the convenience sample was obtained.

\section{Internet use and online purchases}

Survey respondents indicated their main internet connection at home. More than six out of ten had a digital cable connection, while only slightly more than one in ten still used a telephone MODEM, a largely obsolete technology. Thus, for the vast majority, the lack of a fast, dependable internet connection cannot be regarded as a serious limitation to shopping online or on browsing among complex, content-laden online merchant sites.

The median number of hours per week survey respondents reported they spent using the computer at home and at work were ten and eight hours, respectively. Median hours per week on the internet were ten and median time actually shopping online was one hour. About 40 per cent used the computer at home more than ten hours per week, with more than three of ten spending over ten hours per week on the net.

The median value of respondents' most expensive online purchase in the past year was $\$ 200$ and the median value of all online purchases during the preceding year was $\$ 800$. Only slightly more than one in five indicated that their most expensive purchase 
was $\$ 75$ or less, with about the same proportion reporting total purchases for the year of $\$ 200$ or less. On the high side of the spectrum, a fifth of all respondents reported their most costly purchase at more than $\$ 500$ and the same fraction said they had spent more than $\$ 2,000$ in total during the previous year. These data encourage the conclusion that these respondents were, for the most part, more than merely casual shoppers of web offerings.

\section{Price comparison and coupon seeking}

Ten of the most popular online price comparison websites were listed in alphabetical order and respondents were asked how many times in the past year they had visited each site. The results are shown in Table 1. Yahoo! Shopping proved to be the most popular product search and price comparison site listed, with the responding sample divided almost equally between those who never visited, those who visited between 1 and 10 times, and those who visited more than 10 times. Some 22 per cent said they had visited BizRate at least once while 19 per cent indicated so for the Google Product Search site. More than nine out of ten shoppers had never visited the remaining eight product search and price comparison sites.

Visits to coupon supplier sites were even more rare. The MyCoupons site was the most popular, but 85 per cent had never visited it and only 2 per cent had visited it more than ten times. These respondents do not appear to be aggressive coupon seekers.

\section{Reactions to 'track and target'}

The main thrust of this survey was to examine three aspects of consumer shoppers' reactions to online behavioural tracking and to targeting of offers and prices based on the tracking data: what online shoppers and buyers know or believe about these practices, how they feel or evaluate such online marketers' actions, and the manner in which they respond or behave
Table 1: Percentage visiting sites in the past year ${ }^{\star}$

\begin{tabular}{llrl}
\hline Site & Never & $\mathbf{1 - 1 0}$ & Over 10 \\
\hline Price comparison sites & & & \\
Yahoo & 36 & 34 & 29 \\
BizRate & 78 & 19 & 3 \\
Froogle & 81 & 15 & 4 \\
PriceGrabber & 90 & 9 & 2 \\
NexTag & 91 & 7 & 1 \\
DealTime & 94 & 5 & 1 \\
PriceScan & 94 & 5 & 0 \\
PriceRunner & 96 & 4 & 0 \\
MetaPrice & 97 & 2 & 0 \\
PepperJam & 98 & 1 & 0 \\
& & & \\
Coupon sites & & & \\
MyCoupons & 85 & 13 & 2 \\
CoolSavings & 92 & 6 & 1 \\
DealCatcher & 92 & 6 & 2 \\
Entertainment & 92 & 7 & 1 \\
CouponCraze & 96 & 4 & 0 \\
Eversave & 96 & 3 & 1 \\
Consumers Campus & 97 & 2 & 0 \\
CouponMountain & 98 & 2 & 0 \\
FlamingoWorld & 98 & 2 & 0 \\
Keycode & 98 & 2 & 0 \\
\hline
\end{tabular}

${ }^{\star} N=1,135$.

when shopping online under these perceived conditions.

\section{Consumer knowledge and belief}

Sixteen statements about what online can or may do were listed in random order in the survey questionnaire. Respondents registered whether they regarded the statements as true, false, or were unsure. The results are shown in Table 2 with the items listed in the order from that most often to least often seen as true. Ten of the 16 items might be assumed to be actually true. Four items, numbers 11, 14, 15, and 16 in Table 2, can be seen as false, while items 9 and 13 are questionable, depending on how one interprets such words as often, sometimes, or may be.

Less than one out of seven respondents incorrectly regarded the first eight [true] items in Table 2 as false. Nearly 88 per cent correctly indicated that online merchants often save buyer information [item 1], while nearly three-quarters correctly recognised that online marketers might be able to 
Table 2: Percentage who view each statement as true, false, or were unsure*

\begin{tabular}{|c|c|c|c|c|}
\hline & Statement & True & Unsure & False \\
\hline 1 & $\begin{array}{l}\text { Online marketers often save information about the buyers who } \\
\text { purchase from them online. }\end{array}$ & 87.9 & 8.4 & 3.7 \\
\hline 2 & $\begin{array}{l}\text { Online marketers may be able to tell who has previously visited } \\
\text { their site by leaving small programs or 'cookies' on visitors' } \\
\text { computers. }\end{array}$ & 73.7 & 21.8 & 4.6 \\
\hline 3 & $\begin{array}{l}\text { Online marketers can tell whether or not a visitor linked to their } \\
\text { site from a search site such as Google. }\end{array}$ & 70.9 & 22.3 & 6.8 \\
\hline 4 & $\begin{array}{l}\text { Online marketers can keep track of what pages an online shopper } \\
\text { visits on their site whether or not they buy anything. }\end{array}$ & 67.5 & 22.8 & 9.8 \\
\hline 5 & $\begin{array}{l}\text { Online marketers often sell or trade the information they obtain } \\
\text { from people who visit their website. }\end{array}$ & 67.4 & 18.4 & 14.2 \\
\hline 6 & $\begin{array}{l}\text { Online marketers may be able to identify repeat visitors by } \\
\text { recording the IP address or 'ID number' of the shopper's computer }\end{array}$ & 64.9 & 27.8 & 7.3 \\
\hline 7 & $\begin{array}{l}\text { Online marketers can tell how long a shopper stays at their } \\
\text { website on a given visit. }\end{array}$ & 63.4 & 30.4 & 6.2 \\
\hline 8 & $\begin{array}{l}\text { Online marketers sometimes give lower prices to shoppers who } \\
\text { link to their site from 'price-comparison' sites such as BizRate or } \\
\text { Froogle. }\end{array}$ & 44.1 & 42.7 & 13.2 \\
\hline 9 & $\begin{array}{l}\text { Online marketers almost always charge the same price to every } \\
\text { online shopper for the same goods at a given time. }\end{array}$ & 37.3 & 25.9 & 36.8 \\
\hline 10 & $\begin{array}{l}\text { Online marketers sometimes give better deals to 'first-time' buyers } \\
\text { than to those who have purchased from them before. }\end{array}$ & 37.1 & 32.4 & 30.5 \\
\hline 11 & $\begin{array}{l}\text { Online marketers cannot tell anything about visitors to their sites } \\
\text { unless the shopper records some information and submits it. }\end{array}$ & 32.3 & 22.4 & 45.2 \\
\hline 12 & $\begin{array}{l}\text { Online marketers sometimes offer lower prices to shoppers who } \\
\text { previously visited their site once or more without buying. }\end{array}$ & 30.0 & 42.4 & 27.6 \\
\hline 13 & $\begin{array}{l}\text { Online marketers almost always charge less for goods advertised } \\
\text { in email messages with links to their websites. }\end{array}$ & 25.2 & 45.8 & 29.0 \\
\hline 14 & $\begin{array}{l}\text { Online marketers can not tell how many times a shopper has } \\
\text { visited their site if the visitor did not buy anything before. }\end{array}$ & 22.3 & 28.4 & 49.2 \\
\hline 15 & $\begin{array}{l}\text { Online marketers are required by law to charge the same price to } \\
\text { every online shopper for the same goods at a given time. }\end{array}$ & 21.4 & 39.3 & 39.3 \\
\hline 16 & $\begin{array}{l}\text { Online marketers can not tell what items visitors put in their } \\
\text { 'shopping carts' if the shopper leaves the site without buying. }\end{array}$ & 18.0 & 28.8 & 53.2 \\
\hline
\end{tabular}

${ }^{\star} N=1,135$.

identify previous visitors through the deposit of cookies [item 2]. Over two-thirds knew about merchants' ability to identify the site from which visitors came to their site [item 3], as well as their propensity to trade or sell information [item 4]. Uncertainty was most frequent regarding online marketers' giving lower prices to those coming from price comparison sites [item 8]; to previous visitors who were not buyers [item 12]; or to those linking to the site from an e-mail ad message [item 13].

Less than a third erroneously believed they could remain anonymous if they did not register or record any information when visiting a seller's website [item 11]. Similarly, only slightly more than one in five respondents incorrectly indicated that online marketers were legally bound to charge the same price for the same goods at a given time [item 15]. Nearly 40 per cent correctly recognised that was not a legal requirement.

Taken as a whole, these results do not support the view that consumers who are online buyers are a naive lot. While they may be somewhat uncertain or incorrect regarding targeted pricing, the majority is well aware of the potential for collection and application of data obtained from their visits. Obviously, this does not imply that they approve of online marketing measures associated with behavioural tracking and targeting, but it does indicate awareness of such measures. 


\section{Consumer opinions and evaluations}

Respondents to the study expressed their opinions and evaluations by indicating their agreement or disagreement with 16 statements listed in random sequence. They are shown in Table 3 in order from that most often to least often obtaining agreement.

More than eight out of ten would advocate legal prohibition of online marketers' selling information without permission [item 1], while nearly seven in ten agreed there should be a law against collecting and saving data from online shoppers [item 3]. Very nearly the same proportion agreed to a key item central to this study: 'I would be upset if I found out that other shoppers got better deals than I did from the same website during the same time period' [item 2]. Along those same lines, well over half agreed: 'If I learned that an online marketer charged different prices to similar shoppers during a given time I would avoid shopping at that website' [item 7], and nearly as many agreed, 'It should be illegal for online marketers to charge different prices to some shoppers than to others during the same time period' [item 9]. More than half also agreed that if prices fluctuated up and down substantially with subsequent visits within a few hours, they would be very surprised [item 8]. Roughly six out of ten respondents agreed: e-mail ads promoting discounts can be misleading [item 4], and it is easier to find bargains on the net than in stores [item 5], but shopping online is more risky than offline [item 6].

Consistent with the legality issue measured in the previous section, the highest proportion of disagreement was with the statement claiming that it is against the law to charge different prices to different buyers during the same time period [item 16]. Nor did the majority of respondents agree that conventional retails are more fair than online sellers [item 13], or that coupon supplier sites help consumers save [item 14]. Nearly three- fourths disagreed that deleting cookies effectively protects privacy [item 15].

Overall, the results portray a public more opposed than hospitable towards several merchant practices necessary to effective online behavioural tracking and offer or price targeting. That said, it should be noted that in many cases there are substantial minorities who are comfortable or at least tolerant of the practices. These results are contrary to the conventional wisdom, fed by the popular press, that consumers are largely ignorant of the actions of online merchants, blatantly hostile and mistrusting of them, and openly fearful of being exploited. $^{20}$

\section{Online shopping behaviours}

The 16 online shopping actions or practices presented in random order in the questionnaire are shown in Table 4, listed from that most often to the least often reported. Respondents indicated how often they performed each using a verbal frequency scale ranging from 1, Very Often, to 5 , Never. Both the median and modal values are shown.

Using a search site to locate products [item 1] was the single most frequent behaviour online shoppers reported. Recording tracking numbers for delivery of purchases [item 2] was close behind. Respondents also reported that they often check more than one site for comparisons [item 3]; bought mainly from favourite online sellers [item 4]; and read online reviews before buying [item 5]. Among the actions least often taken, respondents reported rarely if ever visited coupon sites [item 16]; 'personalised' seller sites with their own preferences [item 15]; wrote online reviews or sent e-mail of product descriptions from seller sites to others [item 14]; nor did they often forward e-mail product descriptions to friends of family [item 13]. In the mid-range of frequency, the typical respondent sometimes added items to a shopping cart and then left to return 
Table 3: Percentage who agreed and disagreed with each statement ${ }^{\star}$

\begin{tabular}{|c|c|c|c|}
\hline & Statement & Agreed & Disagreed \\
\hline 1 & $\begin{array}{l}\text { Online marketers should be prohibited by law from trading or selling } \\
\text { information about visitors or buyers without their permission. }\end{array}$ & 80.8 & 19.2 \\
\hline 2 & $\begin{array}{l}\text { I would be upset if I found out that other shoppers got better deals than I did } \\
\text { from the same website during the same time period. }\end{array}$ & 78.9 & 21.1 \\
\hline 3 & $\begin{array}{l}\text { There should be a law against online marketers collecting and saving } \\
\text { information about visitors to their sites without the shopper's permission. }\end{array}$ & 68.5 & 31.5 \\
\hline 4 & $\begin{array}{l}\text { E-mail ads with links to 'special discounts' can be misleading because the } \\
\text { prices are often no better than those routinely offered at the website. }\end{array}$ & 62.6 & 37.4 \\
\hline 5 & $\begin{array}{l}\text { It is easier to find bargains and discounts on the web than it is in conventional } \\
\text { retail stores. }\end{array}$ & 62.4 & 37.6 \\
\hline 6 & $\begin{array}{l}\text { Online shopping is generally much more risky than shopping at a conventional } \\
\text { retail store. }\end{array}$ & 59.7 & 40.3 \\
\hline 7 & $\begin{array}{l}\text { If I learned that an online marketer charged different prices to similar shoppers } \\
\text { during a given time I would avoid shopping at that website. }\end{array}$ & 56.7 & 43.3 \\
\hline 8 & $\begin{array}{l}\text { If I visited a website several times within a few hours and the prices fluctuated } \\
\text { up and down substantially I would be very surprised! }\end{array}$ & 55.9 & 44.1 \\
\hline 9 & $\begin{array}{l}\text { It should be illegal for online marketers to charge different prices to some } \\
\text { shoppers than to others during the same time period. }\end{array}$ & 55.2 & 44.8 \\
\hline 10 & $\begin{array}{l}\text { In all fairness, online marketers should offer their loyal customers better prices } \\
\text { and bargains than first-time buyers. }\end{array}$ & 51.5 & 48.5 \\
\hline 11 & $\begin{array}{l}\text { Online shoppers who take the time and trouble to use 'price-comparison' sites } \\
\text { such as PriceScan or Yahoo! deserve to receive lower prices. }\end{array}$ & 49.6 & 50.4 \\
\hline 12 & $\begin{array}{l}\text { Online marketers can learn too much about visitors to their sites, even when } \\
\text { the shopper does not actually enter or submit any information. }\end{array}$ & 49.0 & 51.0 \\
\hline 13 & $\begin{array}{l}\text { Conventional retail stores are generally more fair and honest than online } \\
\text { marketers who sell consumer goods and services. }\end{array}$ & 39.1 & 60.9 \\
\hline 14 & $\begin{array}{l}\text { Websites that specialise in discounts and coupons, such as 'Eversave' or } \\
\text { 'MyCoupons,' allow online shoppers to obtain substantial savings. }\end{array}$ & 37.2 & 62.8 \\
\hline 15 & $\begin{array}{l}\text { Online shoppers can protect their privacy completely if they delete the } \\
\text { 'cookies,' the small programs websites leave on visitors' computers. }\end{array}$ & 26.3 & 73.7 \\
\hline 16 & $\begin{array}{l}\text { It is against the law for online marketers to charge different prices to some } \\
\text { shoppers than to others during the same time period. }\end{array}$ & 19.8 & 80.2 \\
\hline
\end{tabular}

${ }^{*} N=1,135$.

later [item 7] or to never again return [item 8].

Key items for this study, in the order from most often to least often reported, were: 'Return to a site several times to see if better prices are offered.', 'Allow the online merchant to send you email ads and sale bulletins.', 'Link to a site from an email advertisement you received.', and 'Register with the seller's site or "personalize" the seller's web page.' [items 10, 11, 12, and 15, respectively]. All four are directly related to tracking and targeting practices by online merchants. Returning to check for price changes received a median value of 3 , indicating that the most typical respondent reported sometimes doing so; however, for the modal value, the most common rating was 4 , indicating rarely doing so. While the most typical respondent only rarely allowed online merchants to send them e-mail or linked to a site from an e-mail ad, the most common response to registering or personalising a home page was never.

Taken together, the results regarding online shopping behaviour by respondents indicate what might be viewed as fairly typical actions by experienced online buyers - using search engines, tracking deliveries, checking several sites, and reading reviews and the like. Nor could sometimes temporarily or permanently abandoning a shopping cart be regarded as aberrant. By contrast, there appeared to be substantial reluctance by the responding sample to voluntarily and proactively provide information or encourage online merchants to contact them. 
Table 4: Median and modal frequency ratings of online shopping actions*

\begin{tabular}{rlll}
\hline Statement & Median & Mode \\
\hline 1 & Use a search engine or site to locate what you want. & 1 & 1 \\
2 & Record a tracking number when available and track delivery. & 2 & 1 \\
3 & Check more than one site to make comparisons. & 2 & 2 \\
4 & Buy mainly from a 'favorite' online seller. & 2 & 2 \\
5 & Read online reviews of the goods before buying. & 3 & 2 \\
6 & Go to one or more price comparison sites or sellers. & 3 & 3 \\
7 & Add items to the 'shopping cart,' then leave the site and come back later. & 3 & 3 \\
8 & Add items to the 'shopping cart,' then leave without ever returning. & 3 \\
9 & Select a delivery method that's faster than the least costly one. & 3 & 4 \\
10 & Return to a site several times to see if better prices are offered. & 3 & 4 \\
11 & Allow the online merchant to send you e-mail ads and sale bulletins. & 4 & 4 \\
12 & Link to a site from an e-mail advertisement you received. & 4 & 4 \\
13 & Send e-mail product descriptions from the site to family or friends. & 5 \\
14 & Write reviews of previous purchases when the site allows it. & 4 & 5 \\
15 & Register with the seller's site or 'personalize' the seller's web page. & 4 & 5 \\
16 & Visit an online coupon service site to find discount coupons or 'codes.' & 4 & 5 \\
\hline
\end{tabular}

${ }^{*} N=1,135$. Five-point scale: $1=$ Very often, $2=$ Often, $3=$ Sometimes, $4=$ Rarely, $5=$ Never.

\section{CONCLUSIONS}

\section{Consumer awareness}

This study was designed to reveal, in some detail, what consumers know or believe about the practices associated with online merchants' use of online behavioural tracking and the targeting of offers and pricing based on such data. The popular press and some academic reports convey the impression that, unbeknownst to consumers, online marketers engage in nefarious activities behind the scenes, manipulating and exploiting them to the merchants' benefit and the consumers' detriment. ${ }^{20,23,24}$ While such assumptions may provide odder for a dramatic expose, this study provided little or no evidence of such profound ignorance on the public's part. Instead, the survey revealed considerable awareness conditions attendant to behavioural tracking and price targeting; namely, data recording of online activity and application of that data to promotional programmes.

\section{Limitations to generalisation}

This research is based on self-reports by a convenience sample of consumers. The demographic distributions of the sample provided a higher socio-economic profile than that of the population from which the sample was obtained. Generalisations to the public as a whole should be made with caution. As a group, respondents are very probably more knowledgeable and sophisticated regarding online shopping than their less educated or experienced counterparts. Consequently, their awareness and knowledge about online behavioural targeting methods and tactics may be substantially greater than the consumer market as a whole.

There is another factor, the 'suggestibility effect,' that may also tend to inflate the knowledge and awareness picture portrayed in this study. There is the possibility that some behavioural targeting practices may never have occurred to at least a portion of those sampled. Despite this, when presented with a description of the practice, they might respond with an 'I knew that!' reaction, or at least the thought, 'That does sound plausible!' The effects of both the upscale sample and the suggestibility factor tend to inflate the measures of consumer awareness regarding online behavioural tracking practices. 


\section{Consumer evaluations}

There are two basic threads that run through the items measuring consumer approval or disapproval: one has to do with fairness and the other with privacy issues. With regard to fairness, a substantial proportion of consumers appear to be aware of practices associated with online behavioural tracking and offer targeting or the so-called 'dynamic' pricing. Most do not like it! Even though only a fifth thought it was currently against the law, over half thought it should be illegal. Well over half threatened to boycott websites if they learned that it did not follow a 'one-price' policy.

Compared to shopping at a conventional, 'brick and mortar' retail store, respondents found online shopping easier but also more risky. The nature of their perceived risk seems to be mainly in regard to information privacy. While fairness and privacy are distinct areas of concern for consumers, they are inextricably intertwined for online marketers, thus allaying consumer concerns about online behavioural targeting requiring both sets of consumer concerns.

\section{Consumer reactions}

The actions online shoppers in this study reported taking might be seen as reflecting their concern, but not outright alarm.

Although many decried selling or trading of data and dynamic pricing practices, it did not appear to inhibit them greatly while shopping online. While they did not proactively volunteer information about themselves when it was not required, they reported browsing and shopping the net without much regard for what tracking data might be acquired by the sites they visited. Although not completely dismissive of the risks and threats trumpeted by the popular press, it seems clear that 'the rabble' have not been greatly aroused - at least not yet!

Technology-savvy customers do have access to various methods ranging from simple deletion of cookies to varied proxy servers, and other elaborate tools to outwit e-commerce merchants tracking their online moves. The use of such methods by consumers to thwart web visitor tracking will undoubtedly increase somewhat as the public becomes increasingly familiar with the technology. Nonetheless, it appears unlikely that a significant proportion of the public will adopt such elaborate, demanding, and time-consuming procedures.

Product search and price comparison sites are readily available to consumers shopping online. They require little or no expertise or experience to use and the most popular ones provide reports that are easily and clearly understandable. Despite this facility, this study revealed that product search and price comparison sites were used surprisingly infrequently. If the consuming public becomes aware of behavioural tracking and price discrimination and finds it objectionable, it seems more likely that they will turn towards increased use of price comparison facilities than towards the means to obfuscate their online movements and actions.

Ultimately, the consumer reactions that would likely be the most serious and debilitating to commerce merchants would be consumers who turn away from this vibrant and effective channel of distribution. Clearly, there can be no satisfactory, durable relationship between buyer and seller without a sense of trust and confidence on the part of both parties.

\section{Restriction too much}

It seems the nature of legislative bodies and government bureaus to do surgery with an ax. Industry inaction tends to result in government action, often to the detriment of everyone concerned, including both marketers and consumers. Restrictions on online behavioural tracking, offer targeting, and dynamic pricing are likely to handcuff larger, high-profile online merchants while leaving more obscure and perhaps less conscientious online sites to operate 'under the cover of darkness,' so to speak. At the 
very least, legislative restrictions and bureaucratic regulations are certain to add costs that must and will be passed on to consumers.

\section{Disclosure not enough}

Online merchants' industry organisations and some consumer advocacy groups and government bureaus have called for greater disclosure of what data are being collected and compiled and to what use they are being put. Most online marketers do post their 'privacy policy, even if obscure, verbose, and in very small print. On the other hand, very few, if any, online marketers are 'up front' about the use of offer targeting or dynamic pricing. Even when the practice is discovered and reported publicly, some claim it was a mistake, the accusations are unfounded, or they were merely 'testing' a new price.

There is little foundation for the assertion that if consumers know about it, then it is okay to do it. Indeed, knowing the nature and source of abuse, if it exists, makes it no less intolerable. This is not to say that online marketers can safely ignore the call for greater disclosure. It would appear they cannot! The cries will probably only become louder. Resistance only begs the question, 'Why not?' The reasons for concealing what data are acquired and what is done with it are neither obvious nor compelling.

Beyond knowing what online merchants are learning about their shoppers and customers, the consumer must know why the data are being sought and recorded. While there are, in fact, several benefits and advantages to be gained by the consumers whose online behaviour is being tracked, the focus in the media has been almost entirely on the benefits to the merchants. Often, the situation is portrayed as something of a zero sum game: the more the online merchants gain, the more the consumers lose. It is the online marketers and their industry organisations' responsibility to take the initiative in informing and persuading their publics about the benefits this kind of microtargeting has for those being targeted.

\section{References}

1 Burdett, K. and Judd, K. L. (1983) 'Equilibrium price dispersion', Econometrica, Vol. 51, No. 4, p. 955.

2 Bakos, J.Y. (1997) 'Reducing buyer search costs: Implications for electronic marketplaces', Management Science, Vol. 43, No. 12, p. 1676.

3 Neufeld, D. and Parent, M. (2000) 'From bricks to clicks: The risks \& rewards', Ivey Business Journal, Vol. 64, No. 4, p. 72.

4 Steel, E. (2007) 'How marketers hone their aim online; consumer-specific ads gain in popularity due to new efficiencies', Wall Street Journal. 19th June, 2007; Sect B, p. 6.

5 Burke, K. (2004) 'Ensemble selling online', Target Marketing, Vol. 27, No. 11, p. 29.

6 Burke, R. R. (2002) 'Technology and the customer interface: What consumers want in the physical and virtual store', Academy of Marketing Science Journal, Vol. 30, No. 4, p. 411.

7 Sen, R., King, R. C. and Shaw, M. J. (2006) 'Buyers' choice of online search strategy and its managerial implications', Journal of Management Information Systems, Vol. 23, No. 1, p. 211.

8 Goff, C. (2006) 'Behavioural targeting: Following footsteps', New Media Age, 16th February, p. 23.

9 Wasserman, T. (2007) 'Yahoo! Bets big on behavioral', Brandweek, Vol. 48, No. 18, p. 8.

10 Feinberg, F. M., Krishna, A. and Zhang, Z. J. (2002) 'Do we care what others get? A behaviorist approach to targeted promotions', JMR, Journal of Marketing Research, Vol. 39, No. 3, p. 277.

11 Miles, L. (1990) 'Direct marketing: Initiative tests', Marketing, 25th January, p. 39.

12 Nash, E. (1995) 'The roots of direct marketing', Direct Marketing, Vol. 57, No. 10, p. 38.

13 Otim, S. and Grover, V. (2006) 'An empirical study on web-based services and customer loyalty', European Journal of Information Systems, Vol. 15, No. 6, p. 527.

14 Pitta, D., Franzak, F. and Fowler, D. (2006) 'A strategic approach to building online customer loyalty: Integrating customer profitability tiers', The Journal of Consumer Marketing, Vol. 23, No. 7, p. 421.

15 Cassidy, M. (2007) 'Remarketing 101', Mediaweek, Vol. 17, No. 20, p. 12.

16 Chen, Y. and Sudhir, K. (2004) 'When Shopbots meet emails: Implications for price competition on the internet', Quantitative Marketing and Economics, Vol. 2, No. 3, p. 233.

17 Kocsis, J. and Banks, A. (2005) 'Demystifying targeted online marketing', LIMRA's MarketFacts Quarterly, Vol. 24, No. 1, p. 72.

18 Rigby, E. (2005) 'On target', Revolution, December, p. 75. 
19 Garbarino, E. and Lee, O. F. (2003) 'Dynamic pricing in Internet retail: Effects on consumer trust', Psychology \& Marketing, Vol. 20, No. 6, p. 495.

20 Turow, J., Feldman, L. and Meltzer, K. (2005) 'Open to exploitation: American shoppers online and offline', University of Pennsylvania's Annenberg School for Communication, Philadelphia.

21 Bosworth, M. H. (2006) 'Consumerists want FTC probe of online advertising', consumeraffairscom., 20th November.
22 Campanelli, M. (2006) 'FTC studies technology, privacy issues', DM News, 20th November.

23 Kadet, A. (2006) 'Buyer beware', SmartMoney, May, pp. $90-5$.

24 Koprowski, B. G. (1998) 'Buying the goods The (New) hidden persuaders: What marketers have learned about how consumers buy on the web', Wall Street Journal, 7th December 1998; Sect R, p. 10. 